\title{
Evaluation of attitudes and thoughts of fifth grade medical faculty students towards psychiatry before and after psychiatry internship
}

Tıp fakültesi beşinci sınıf öğrencilerinde psikiyatri stajı öncesi ve sonrasında psikiyatriye yönelik tutum ve düşüncelerinin değerlendirilmesi

\author{
(iD) Halil Ibrahim Tas ${ }^{\text {a }}$ (iD) Hulya Ertekin ${ }^{\mathrm{a}}$ \\ ${ }^{\text {a }}$ Canakkale Onsekiz Mart University, School of Medicine, Department of Psychiatry, Canakkale, Turkey
}

\begin{abstract}
Introduction: We aimed to evaluate of attitudes and thoughts of 5th grade medical faculty students towards psychiatry before and after psychiatry internship in this study.

Methods: Of fifth grade, 65 student of Canakkale Onsekiz Mart University Faculty of Medicine participated in this study. These students were asked to fill out the questionnaire of "Attitudes and Thoughts towards Psychiatry" before and after the psychiatric internship. This questionnaire consists of 38 questions, about attitudes towards psychiatry, psychiatric treatment and psychiatrists. The SPSS Package Program 20.0 statistical program was used for data analysis. Kolmogorov-Smirnov, Shapiro Wilk and Paired Samples Test were used.

Results: $64.3 \%(n=36)$ of the study group were female, and $35.7 \%(n=20)$ of the study group were male. $49.0 \%$ of the students preferred "internal sciences", $49.0 \%$ preferred "surgical sciences", and 2.0\% "basic sciences". A total 14 questions from 38 questions were found to be statistically significant after the internship.

Conclusion: It was observed that there were positive attitudes about the benefits of psychiatric treatment and consultation services after the internship compared to the pre-internship, decreased negative thoughts about psychiatric patients and psychiatristsin students of faculty of medicine. Despite the generally positive changes in psychiatric science, decreased preference of psychiatry have been observed in students of faculty of medicine.
\end{abstract}

Keywords: Medical faculty, psychiatry, medical student, attitudes, internship

\section{ÖZ}

Giriş: $\mathrm{Bu}$ çalışmada tıp fakültesi 5. sınıf öğrencilerinde psikiyatri stajı önce ve sonrasında psikiyatriye yönelik tutum ve düşüncelerinde değişiklikler olup olmadığını irdelemeyi amaçladık.

Yöntem: Araştırmada Çanakkale Onsekiz Mart Üniversitesi Tıp Fakültesi 5. sınıf öğrencisi olan 65 öğrenci katılmıştır. Bu öğrencilerden psikiyatri staj1 öncesi ve sonrasında 'Psikiyatriye yönelik tutum ve düşünceler' anketi doldurmaları istenmiştir. 38 sorudan oluşan ankette psikiyatri, psikiyatrik tedavi ve psikiyatristlere yönelik tutumlar hakkında sorular bulunmaktadır. Analizlerde SPSS Paket Program 20,0 sürümü kullanılmıştır. Kolmogorov-Smirnov, Shapiro Wilk ve Paired Samples Test kullanıldı.

Bulgular: Çalışma grubunun \%64,3'ü kadın (n=36), \%35,7'si (n=20) erkekti. Uzmanlık alanı olarak öğrencilerin \%49,0’u “dâhili bilimleri”, $\% 49,0$ ’u "cerrahi bilimleri”, \%2,0'si “temel bilimleri” tercih etmekteydi. Toplam 38 anket sorusundan 14'ünde staj öncesine göre staj sonrasında anlamlı fark bulundu.

Sonuç: Tıp fakültesi öğrencilerinde, staj öncesine göre staj sonrasında psikiyatrik tedavi ve konsültasyon hizmetlerinin yararları konusunda olumlu tutum değişikliklerinin olduğu, psikiyatri hastaları ve psikiyatristler hakkında olumsuz düşüncelerin azaldığı, psikiyatri bilimi hakkında genel olarak olumlu değişimlere rağmen uzmanlık alanı olarak tercih edilmesinde azalma olduğu görülmüştür.

Anahtar kelimeler: Tıp fakültesi, psikiyatri, tıp öğrencisi, tutumlar, staj

Submission: Jan 15, 2018

Acceptance: Mar 02, 2018

E-Mail: md.ertekin@gmail.com

Correspondence: Hulya Ertekin, MD, Canakkale Onsekiz Mart University, School of Medicine, 5th floor, Canakkale-Turkey 


\section{Giriş}

Tutumlarımız genellikle bireylere atfedilen ve olgularla ilişkili olarak bir uyarana verilen duygu, düşünce ve davranışlarımızı şekillendiren eğilimlerimizdir. Öte yandan bu tutumlar halk kültüründen gelen ve deneyimlerle değişikliğe uğrayabilen süreçlerdir [1]. Psikiyatri ve ruhsal bozukluklar konusunda toplumun bakış açısı yıllardır üzerinde çalışılan ve ilgi çeken bir konu olmuştur. Ruhsal bozukluğu olan kişiler daha tehlikeli korkutucu ve garip olarak algılanabilmektedir. Bu nedenle ruhsal bozukluğu olan bireyler hak etmediği ve insancıl olmayan davranışlarla karşı karşıya kalabilmektedir [2]. Ülkemizde yapılan çalışmalarda halkın ruhsal bozukluklar ile ilgili olarak bilgilerinin yetersiz olduğu ve ruhsal bozukluğu olan kişilere karşı etiketleyici ve damgalayıcı oldukları bildirilmiştir. Bu durumun kuşkusuz en önemli sonucu ise akıl sağlı̆̆ ile ilgili tedavi arayışı veya tedaviyi sürdürmenin etiketlenme korkusu ile yapılamayacak olmasıdır [3, 4]. Sağlık çalışanlarının psikiyatriye yönelik tutumları değerlendirildiğinde; ruh sağlığı bozukluğu olan bireyleri tehlikeli ve saldırgan buldukları ve şizofreni hastalarına karşı tutumlarının olumsuz olduğu bildirilmektedir [5]. Birinci basamak hekimlerinin değerlendirildiği çok merkezli bir çalışmada, hekimlerinin yarıdan fazlası şizofreni hastası olan bireylerin toplum içinde serbest dolaşmamaları gerektiği, kendi hayatları ile ilgili doğru karar alamayacaklarını ve saldırgan olduklarına inandıklarını bildirmiştir [1]. Sağlık çalışanlarının ruhsal bozukluğu olan bireylere olan bakışındaki çelişkili durum tıp öğrencilerinde de benzer şekilde görünmektedir. Tıp öğrencilerinin ruhsal bozukluğu olan bireylere bakış açısı ve psikiyatrinin saygınlığı konusundaki düşünceleri ile ilgili yapılmış bazı çalışmalarda, tıp eğitiminin ruhsal bozukluğu olan bireylere karşı tutumda olumlu etkilere yol açtığı bazı çalışmalarda etkisi olmadığı bildirilmiştir [4, 6-9]. Geleceğin hekimleri olacak tıp fakültesi öğrencilerinin psikiyatrik hastalıklar konusunda takınacağı olumlu tutum veya olumlu değişim için tıp eğitimi süreci ve toplum temelli yaklaşımlara önem verilmesi gerektiğini söylemek mümkündür [10].

Bu bilgiler ışı̆̆ında; tıp fakültesi 5. sınıf öğrencilerinde, psikiyatri stajından önce ve sonra psikiyatriye yönelik tutum ve düşüncelerin ne olduğunu ve bu süreç içerisinde tutum ve düşüncelerinde değişiklikler olup olmadığını irdelemeyi amaçladık.

\section{Yöntem}

\section{Örneklem seçimi ve gereçler}

Araştırmaya Çanakkale Onsekiz Mart Üniversitesi Tıp Fakültesi 5. sınıf öğrencisi olan 65 öğrenci katıldı. Bu öğrencilerden toplamda üç hafta süren psikiyatri stajı öncesi ve sonrasında anket doldurmaları istendi. Veri toplama aşamasında araştırma amacı anlatıldı ve gönüllü olanlardan onay alındı. Çanakkale Onsekiz Mart Üniversitesi Tıp Fakültesi Etik kurulundan onam alındı. Anket çalışmasına katılması talep edilen öğrencilere herhangi bir ödül veya yaptırım uygulanmadı. Öğrencilerden doldurulması istenen 'Psikiyatriye yönelik tutum ve düşünceler' anketi, Nielsen ve ark. tarafından oluşturulmuş, Balon ve ark. tarafından geliştirilmiş, ankete ek sorular yerleştirilerek Altınbaş ve ark. tarafından Türkçe'ye uyarlanmıştır [11-13]. 38 sorudan oluşan ankette psikiyatri, psikiyatrik tedavi, psikiyatristlere yönelik tutumların sorulduğu birden dörde kadar 'kesinlikle katılıyorum' cevabından 'kesinlikle katılmıyoruma' uzanan cevaplar bulunmaktadır.

\section{İstatistiksel Analiz}

Veriler SPSS Paket Program 20,0 sürümü ile analiz edildi. Tanımlayıcı verilerin sunumunda sayı, yüzde, ortalama, standart sapma kullanıldı. Niceliksel verilerin normal dağılıma uygunluğu Kolmogorov-Smirnov Testi ve Shapiro Wilk Testi ile değerlendirildi. Eş grupların karşılaştırılmasında Paired Samples Test kullanıldı. İstatistiksel anlamlılık için $p<0,05$ kabul edildi.

\section{Bulgular}

Çalışma grubunun \%64,3 (n=36)'ü kadın, \%35,7 (n=20) 'si erkekti. Uzmanlık alanı seçimi sorusuna stajyer öğrencilerin \%87,5'i “evet”, \%12,5'i "hayır" yanıtlarını verdi. Uzmanlık alanlarını seçtiklerini ifade eden ögrencilerin \%49,0’u "dâhili bilimleri”, \%49,0'u "cerrahi bilimleri”, \%2,0'si "temel bilimleri” tercih etmekteydi. Katılımcıların \%30,4’ü (n=17) ailede psikiyatrik bir hastalık öyküsü olduğunu belirtti. Çalışma grubumuzda yer alan öğrencilerin staj öncesi ve sonrası ortalama puanlarındaki değişim Tablo 1'de ve Tablo 2'de sunulmuştur. Madde 4, 5, 6, 8, 13, 14, 17, 23, 30, 32, 34, 35, 36, 37 ortalama puanları arasında staj sonrasında staj öncesine göre istatistiksel anlamlı bir fark bulundu.

Tablo 1. Katılımcıların staj öncesi ve sonrasında anket sorularındaki ortalama puanlarındaki değişim

\begin{tabular}{|c|c|c|c|}
\hline \multicolumn{2}{|c|}{ Staj öncesi (0) ve sonrası (S) maddeler } & \multirow{3}{*}{$\begin{array}{c}\begin{array}{c}\text { Ortalama } \pm \text { Standart } \\
\text { sapma }\end{array} \\
1,41 \pm 0,63 \\
1,05 \pm 0,30\end{array}$} & \multirow{2}{*}{$p$ değeri* } \\
\hline $\mathrm{O} 4$ & \multirow[t]{2}{*}{ Ailemden birisi duygusal olarak altüst olmuşsa psikiyatrik destek almasını öneririm. } & & \\
\hline S4 & & & $<0.001$ \\
\hline $\mathrm{O} 5$ & \multirow[t]{2}{*}{ Psikiyatrik konsültasyon cerrahi ve diğer tıbbi hastalar için sıklıkla yararlıdır } & $1,66 \pm 0,75$ & \multirow[b]{2}{*}{0.001} \\
\hline S5 & & $1,34 \pm 0,48$ & \\
\hline O6 & \multirow[t]{2}{*}{ Psikiyatrik tedavi, psikiyatrik tedavi alan hastaların çoğunda yararlıdır } & $2,05 \pm 0,70$ & \multirow[b]{2}{*}{$<0.001$} \\
\hline S6 & & $1,63 \pm 0,52$ & \\
\hline $\mathrm{O} 8$ & \multirow[t]{2}{*}{ Psikiyatristlerin çoğu net ve mantıklı düşünürlerdir } & $2,16 \pm 0,65$ & \multirow[b]{2}{*}{$<0.001$} \\
\hline S8 & & $1,79 \pm 0,68$ & \\
\hline $\mathrm{O} 13$ & \multirow{2}{*}{$\begin{array}{l}\text { Psikiyatri fazlası ile analitik, teorik ve psikodinamiktir ve hastanın fizyolojisine yeterince } \\
\text { eğilmez }\end{array}$} & $3,68 \pm 0,47$ & \multirow[b]{2}{*}{0.034} \\
\hline S13 & & $3,80 \pm 0,40$ & \\
\hline $\mathrm{O} 14$ & \multirow{2}{*}{$\begin{array}{l}\text { Psikiyatristler, hastaları istemsiz olarak hastaneye yatırmak için çoğunlukla yasal } \\
\text { yetkilerini kötüye kullanırlar }\end{array}$} & $3,64 \pm 0,55$ & \multirow[b]{2}{*}{0.006} \\
\hline S14 & & $3,86 \pm 0,40$ & \\
\hline $\mathrm{O} 17$ & \multirow[t]{2}{*}{ Psikiyatri diğer tıbbi disiplinler arasında yüksek prestije sahiptir } & $2,66 \pm 0,84$ & \multirow[b]{2}{*}{$<0.001$} \\
\hline S17 & & $2,27 \pm 0,80$ & \\
\hline
\end{tabular}

* Paired Samples Test, O:Öncesi, S: Sonra 
Tablo 2. Staj öncesi ve sonrasında maddelerin ortalama puanlarındaki değişim, Çanakkale, 2017

\begin{tabular}{|c|c|c|c|}
\hline \multicolumn{2}{|c|}{ Staj öncesi (0) ve sonrası (S) maddeler } & \multirow{3}{*}{$\begin{array}{c}\begin{array}{c}\text { Ortalama } \pm \text { Standart } \\
\text { sapma }\end{array} \\
2,41 \pm 0,71 \\
2,95 \pm 0,84 \\
\end{array}$} & \multirow{3}{*}{$\begin{array}{r}p \text { değeri* } \\
<0.001\end{array}$} \\
\hline $\mathrm{O} 23$ & \multirow[t]{2}{*}{ Psikiyatri hastalarının yanında kendimi huzursuz hissederim } & & \\
\hline S23 & & & \\
\hline $\mathrm{O} 30$ & \multirow[t]{2}{*}{ Psikiyatrik hastalar duygusal olarak tüketicidir } & $2,48 \pm 0,83$ & \multirow[b]{2}{*}{0.044} \\
\hline S30 & & $2,70 \pm 0,91$ & \\
\hline $\mathrm{O} 32$ & \multirow[t]{2}{*}{ Psikiyatrik hastalıklar en az fiziksel hastalıklar kadar dikkati hak eder } & $1,38 \pm 0,49$ & \multirow[b]{2}{*}{0.001} \\
\hline S32 & & $1,13 \pm 0,43$ & \\
\hline $\mathrm{O} 34$ & \multirow[t]{2}{*}{ Psikiyatrik tedaviler tıbbın diğer branşlarındaki tedaviler kadar etkilidir } & $3,39 \pm 0,76$ & \multirow[b]{2}{*}{0.004} \\
\hline S34 & & $3,63 \pm 0,65$ & \\
\hline $\mathrm{O} 35$ & \multirow[t]{2}{*}{ Psikiyatristlerin hastaları için yapabileceği çok az şey vardır } & $1,91 \pm 0,79$ & \multirow[b]{2}{*}{0.002} \\
\hline S35 & & $1,59 \pm 0,63$ & \\
\hline $\mathrm{O} 36$ & \multirow[t]{2}{*}{ Parlak bir öğrenciyi psikiyatriye girmesi için teşvik ederim } & $2,96 \pm 0,83$ & \multirow[b]{2}{*}{$<0.001$} \\
\hline S36 & & $3,50 \pm 0,69$ & \\
\hline $\mathrm{O} 37$ & \multirow{2}{*}{$\begin{array}{l}\text { Psikiyatrist olmak isteyenler genellikle kendi kişisel sorunları nedeniyle psikiyatriye ilgi } \\
\text { duyarlar }\end{array}$} & $2,11 \pm 0,80$ & \multirow[b]{2}{*}{$<0.001$} \\
\hline S37 & & $1,84 \pm 0,68$ & \\
\hline
\end{tabular}

* Paired Samples Test, O:Öncesi, S: Sonra

\section{Tartışma}

Çalışmamızda tıp fakültesi 5. Sınıf öğrencilerinin genel olarak psikiyatriye yönelik tutum ve düșüncelerinde, psikiyatri stajı öncesi ve sonrasındaki düşüncelerde belirgin değişiklikler olduğu görüldü. Özellikle psikiyatrik tedavinin hastalara yararları konusunda tutum değişikliklerinin olduğu, psikiyatrik hastalar hakkındaki bazı önyargılarının değiştiği ve psikiyatristler hakkındaki düşüncelerinde staj öncesi ve sonrasında değişiklikler olduğu görüldü.

Genel toplumda psikiyatrik tedavi ile ilgili farklı görüşler mevcut olup, bazı çalışmalar katılımcıların, ruhsal hastalıkların sağaltımında psikoterapi ve ilaç tedavisinin yararlı olduğunu düşündüklerini gösterirken $[14,15]$; bazı çalışmalardaki katılımcılar ise psikiyatrik tedavinin zararlı olduğunu bildirmişlerdir $[16,17]$. Tedavi uygulamaları içinde ise psikoterapi uygulamalarının ilaç tedavisine göre daha fazla tercih edildiği gösterilmiştir [18]. Genel toplumda psikiyatrik tedaviler konusundaki tutumlar sağlık çalışanlarında da değerlendirilmiştir. Birinci basamak hekimlerinin şizofreni ve tedavisine yönelik bakıș açılarının değerlendirildiği bir çalışmada, hekimlerin dörtte üçünden fazlası şizofreninin tam olarak düzelmeyeceğini düşünmüşlerdir. Şizofreninin bir hastalık olduğunu düşünenlerin yarıdan fazlası hastalığın tedavisinin mümkün olduğunu düșünmekte fakat büyük çoğunluğu bu ilaçların bağımlılık yapabileceğini ve ciddi yan etkilerinin olduğunu belirtmiștir. Aynı çalıșmada hekimlerin dörtte üçü şizofreni olan bireylerin saldırgan olacağına inandığı ve bu hastalar ile aralarına sosyal mesafe koyulması gerektiğini bildirmişlerdir [1]. Psikiyatriye yönelik tutumların öğrencilerde değerlendirildiği bir çalışmada hemşirelik öğrencilerinin psikiyatriye yönelik tutumlarının olumlu olduğu saptanmıştır [19] Tıp öğrencilerinin, psikiyatrik tedavi ve sonuçları ile ilgili görüşleri hakkında farklı sonuçlar mevcuttur. Tıp öğrencileri, bazı çalışmalarda psikiyatrik tedavinin etkisiz olduğunu düşündüğünü bildirilirken, bazı çalışmalarda ise tıp öğrencilerinin psikiyatrik ilaçların etkisi konusunda, genel topluma oranla daha olumlu görüşte oldukları bildirilmiştir $[20,21]$. Ülkemizde yapılan bir çalışmada tıp öğrencilerinin aldıkları eğitim sonrasında psikiyatrik hastaların çevreye ve yakınlarına zarar verme ihtimalleri nedeniyle kısıtlanmaları gerektiği düşüncelerinde öncesine göre azalma olduğu bildirilmiștir [6]. Bizim çalıșmamızda öğrencilerin psikiyatri hastalarının yanında kendilerini huzursuz hissetmeleri ve psikiyatri hastalarının duygusal olarak tüketici olduğu inancı ile ilgili sorulara verilen cevaplarda, staj sonrasında bu inanışlarında azalma görülmüştür. Psikiyatrik hastalıkların en az fiziksel hastalıklar kadar dikkate değer olduğu, psikiyatrik tedavi ve psikiyatri konsültasyonunun yararlı olduğu sorularına verilen yanıtlarda ise öğrenciler staj öncesine göre bu fikre daha çok katıldıklarını belirtmişlerdir. Bu olumlu değişim öğrencilerin staj sırasında verilen pratik eğitimi ile psikiyatri servisinde psikiyatri hastalarını birebir değerlendirebilmeleri ile açıklanabilir. Değișim ayrıca staj süresince yatarak tedavi gören ve poliklinikte takip edilen hastalara verilen tedavilerin olumlu sonuçlarını takip edebilmelerinin etkisi olarak öğrencilerdeki olası önyargıların azalmasına bağlı olabilir. Her ne kadar psikiyatri ile ilgili klinik pratik bilgisi 5. sınıf ve 6 . sınıfta edinilse de fakültemiz 1. ve 3. dönem müfredatında ruh sağlı̆̆ı ve hastalıkları ile ilgili teorik bilgilendirme yapılmaktadır. Bu nedenle 5. sınıf psikiyatri stajına başlamadan önce 5. sınıf öğrencilerinin ruh sağlığı ve hastalıkları konusunda edinmiş oldukları teorik bilgiler, kişilerin konu ile ilgili tutumlarını etkilemiş olabilir.

Genel toplumda ruh sağlığı ve hastalıkları uzmanı algısı genel olarak olumsuz olup bu durum psikiyatristlerin aldığı eğitim, uzmanlık amaçları hakkındaki bilgilerin yetersizliğine bağlanmaktadır. Psikiyatrist ve psikologlar arasındaki ayırım konusunda genellikle zorluk yaşanmaktadır. Psikiyatristlerin tıp doktoru olduğu bilinmemektedir. Sağlık çalıșanları arasında da psikiyatristlerin statülerinin düşük olduğu kanısı vardır [21]. Psikiyatriye başvuran hastalar ile genel toplumun karşılaştırıldı̆̆ çalışmada, psikiyatristler ile ilgili sorular sorulmuştur. Anket sonuçlarında toplumun yaklaşık yarısı ile ayaktan psikiyatriye başvuran hastaların \%36'sı, psikiyatristlerin hekim olduğunu bilememişlerdir [22]. Hekimlerin ruhsal sorunlarda medikal tedaviyi tercih ettiği, insanların da ruh sağlığı sorunu ile karşılaştığında yakın çevresi ile dertleşme eğiliminde olduğu bildirilmektedir [1]. Psikiyatristler hakkında kalıplaşmış düşüncelerden bazıları da delilik, tuhaflık ve istismarcı olabileceği ile ilgili düşüncelerdir [21]. Bu düşüncelerden en yaygın olanı, psikiyatristlerin kendilerinin ruh sağlığı sorunları yaşadığıdır [24]. Tıp öğrencilerinin psikiyatristlere bakış açısına bakıldığında, diğer disiplinlerdeki uzmanlara göre tutarsız ve nevrotik oldukları, psikiyatristleri anlaşılması zor kafası karışık ve karmaşık olarak değerlendirdikleri bildirilmiştir $[21,25]$. Çalışmamızda psikiyatristlerin çoğunun net ve mantıklı düşünürler olduğu ile ilgili inançlarında staj öncesine göre sonrasında artış gözlenmiştir. Bu değişimin nedeni; tıp öğrencilerinin 5. sınıfa gelene kadar gerek psikiyatri ile ilgili derslerde öğretim üyeleri tutumlarını gözlemlemeleri ve klinik uygulamalara geçildiğinde psikiyatri asistanlarının olumlu tutumlarının gözlenmesi sonucu olarak yorumlanabilir. Psikiyatristlerin, hastaları istemsiz olarak hastaneye yatırmak için çoğunlukla yasal yetkilerini kötüye kullandıkları ile ilgili inançlarda staj öncesine göre sonrasında azalma olmuştur. Daha önce psikiyatri stajı almamış tıp fakültesi öğrencilerinde ve psikiyatri dışı sağlık çalışanlarında psikiyatrik hastalıklar konusundaki bilgi eksikliği, psikiyatristlerin yasal yetkileri hakkındaki önyargılarını açıklıyor olabilir. Psikiyatrist olmak isteyen kişilerin garip ve nevrotik kişiler olduğu inancıyla ilgili sorulara verilen yanıtta staj öncesinde ve sonrasında değişiklik olmamıştır. Fakat psikiyatrist olmak isteyenlerin kişisel sorunları olan insanlar olduğu ile ilgili inançlarda, staj öncesine göre staj sonrasında artış olduğu gözlenmiştir. Bu değişimde tıp fakültesi öğrencilerinin staj boyunca karşılaştığı psikiyatri profesyonellerinden aldıkları geri bildirimler 
etkili olmuş olabilir. Bu değişim konusunda genelleme yapabilmek için psikiyatri dışı uzmanlık alanlarında da hekimlerin benzer şekilde sınanması gerekmektedir.

Sağlık çalışanları arasında psikiyatristleri düşük statülü olarak kabul edenler azımsanmayacak orandadır [21]. Seçilen uzmanlık dalının bırakılması ile ilgili yapılan çalışmada psikiyatri uzmanlığını bırakma nedeni olarak düşük statüsü ve diğer sağlık çalışanları açısından daha az saygı duyulması olarak değerlendirilmiştir [26]. Buna karşın İngiltere'de yapılmış çalışmada entelektüel tatmin açısından psikiyatrinin ilk sıralarda yer aldığı belirtilmiştir [27]. Tıpta uzmanlık sınavına hazırlanan tıp öğrencilerinin psikiyatri asistanlığı hakkında tutumlarının değerlendirildiği bir çalışmada psikiyatriyi diğer tıp uzmanlıklarına göre daha az prestijli bulanların oranı $\% 12,4$ iken, katılımcıların yarısı bu görüşe katılmadığını ifade etmiştir. Aynı çalışmada katılımcıların yarısının psikiyatri hekimliğini maddi açıdan doyurucu bulduğu bildirilmiştir [28]. Tıp öğrencilerinin psikiyatriye yönelik tutumları konusundaki sonuçlar çelişkili gibi görünmektedir. Dört ayrı tıp fakültesinde yapılmış çalışmada tıp fakültesi öğrencilerinin psikiyatriye yönelik tutumları genel olarak olumlu iken, istisna olarak psikiyatri hekimlerinin düşük maaş alması ve diğer tıbbi disiplinlerin psikiyatriye bakış açısında olumsuz düşündükleri bildirilmiştir [12]. Tıp fakültesi öğrencilerinde psikiyatri eğitimi tamamlandıktan sonra psikiyatriye yönelik tutumların değerlendirildiği bazı çalışmalarda olumlu değişiklikler olduğu bildirilmiştir [7, 29, 30]. Bazı çalışmalarda ise tıp öğrencilerinin psikiyatriye yönelik tutumlarında, psikiyatri staj eğitimi sonrasında hiçbir değişiklik olmadığını göstermiştir [31]. Genel olarak psikiyatriye yönelik tutumlar olumlu olsa da uzmanlık dalı olarak psikiyatriyi tercih etmek isteyen tıp öğrencilerinin oranında düşüklük göze çarpmaktadır [32]. Uzmanlık alanı olarak psikiyatriyi tercih etmeme nedeni olarak, diğer tıp bölümleri arasında psikiyatriye karş1 prestij ve saygınlığın daha düşük olduğu algısından kaynaklandığı bildirilmektedir [33]. Bu tutumların nedeni de tıp öğrencilerinin psikiyatriyi bilimsel temelleri olmayan bir bilim olarak görmeleri ve iş tatmininin daha az olduğu düşüncesidir [34]. Bunun yanında tanı ile ilgili belirsizlikler de psikiyatriye karşı ilgiyi azaltabilir [26]. Çalışmamızda psikiyatriye yönelik tutumlarda staj öncesi ve sonrası tutumlarda değişimin olduğu üç soru göze çarpmaktaydı. Öğrencilerde psikiyatrinin fazlası ile analitik, teorik ve psikodinamik bir dal olduğu düşüncesi ile psikiyatri bilim dalının hasta fizyolojisine yeterince eğilmediği düşüncesinde staj sonrasında öncesine göre azalma olmuştur. Ruhsal bozuklukların biyolojik mekanizmalarının son dönemlerde yapılan çalışmalarla daha iyi açıklanması bu düşüncelerdeki olumlu yönde değişimi açıklayabilir. Ayrıca "psikiyatri diğer tıbbi disiplinler arasında yüksek prestije sahiptir" sorusuna verilen yanıtta tıp öğrencilerinin bu düşünceye staj sonrasında öncesine göre daha fazla katıldıkları görülmüştür. Psikiyatriye yönelik olumlu inanışlarda artış olmasına rağmen ilginç bir şekilde öğrenciler "Parlak bir öğrenciyi psikiyatriye girmesi için teşvik ederim" düşüncesine staj öncesine göre sonrasında daha az katıldıklarını belirtmişlerdir. Tıp fakültesi öğrencilerinin psikiyatriye karşı tutumlarındaki genel olarak olumlu değişime rağmen, psikiyatri uzmanlığını hala tercih etmemelerinin nedeni ekonomik kaygılar olabilir.

Bu çalışmanın bazı kısıtlılıkları bulunmaktadır. Çalışmaya katılan öğrencilerin sosyodemografik verilerde doğdukları, yetiştikleri ve yaşadıkları yer kısımlarını eksik doldurmaları nedeniyle tutum için önem arz eden bu etken konusunda yorum yapılamamıştır. Fakültemiz ilk üç dönemi müfredatında ruh sağlığına giriş ve ruh sağlığı hastalıkları ile ilgili bilgiler öğretilmekte olup çalışmamızda sadece 5. dönem psikiyatri stajı öncesi ve sonrasına odaklanılmış olması, çalışma bulgularımızı etkilemiş olabilir. Öğrencilere verilen soru formunda kapalı uçlu sorular sorulduğu için bazı maddelerde kavram karmaşası yaşamış olabilirler.

Sonuç olarak bu çalışma Tıp fakültesi öğrencilerinde, staj öncesine göre staj sonrasında psikiyatrik tedavi ve konsültasyon hizmetlerinin yararları konusunda olumlu tutum değişikliklerinin olduğunu, psikiyatri hastaları ve psikiyatristler hakkında olumsuz düşüncelerin azaldığını, psikiyatri bilimi hakkında genel olarak olumlu değişimlere rağmen uzmanlık alanı olarak tercih edilmesinde azalma olduğu göstermiştir. Ek olarak tek bir tıp fakültesinde verilen özenli bir eğitim sonrası saptanan değerli değişimin ülkemize ya da genel tıp fakültesi öğrenci kitlesine genellenebilmesi zorluklar içermektedir. Bu nedenle de ülkemizdeki birçok tıp fakültesinin katılımıyla planlanacak daha büyük çalışmalara gereksinim vardır.

\section{Çıkar çatışması / Conflict of interest: Yok / none.}

Finansal destek / Funding: Yok / none.

\section{Kaynaklar}

1. Aker T, Özmen E, Ögel K, ve ark. Birinci basamak hekimlerinin şizofreniye bakış açısı. Anadolu Psikiyatri Dergisi. 2002;3(1):2002:5-13.

2. Bostancı N. Ruhsal bozukluğu olan bireylere yönelik stigma ve bunun azaltılmasına yönelik uygulamalar. Dusunen Adam The Journal of Psychiatry and Neurological Sciences 2005;18:32-38.

3. Sağduyu A, Aker T, Özmen E, ve ark. Halkın şizofreniye bakışı ve yaklaşımı üzerine bir epidemiyolojik araştırma. Türk Psikiyatri Dergisi. 2001;12(2):99-110.

4. Arkar H, Eker D. Akıl hastalıkları ile ilgili tutumlar: Psikiyatri stajının etkisi. Psikiyatri Psikoloji Psikofarmakoloji (3P) Dergisi; 1998;6(4):263-270.

5. Bağ B, Ekinci M. Sağlık personelinin ruhsal sorunları olan bireylere yönelik tutumlarının araştırılması. Elektronik Sosyal Bilimler Dergisi. 2005;11(3):107-127.

6. Birdoğan SY, Berksun OE. Tıp fakültesi 1. Sınıf ve 6. sınıf öğrencilerinde psikiyatrik hastaya yönelik tutumlar. Kriz Dergisi. 2002;10(2):17. https://doi.org/10.1501/Kriz_0000000184

7. Holm-Petersen C, Vinge S, Hansen J, et al. The impact of contact with psychiatry on senior medical students' attitudes toward psychiatry. Acta Psychiatrica Scandinavica. 2007;116(4):308-11. https://doi.org/10.1111/j.1600-0447.2007.01036.x

8. Erbaydar P, Çilingiroğlu N. Tıp Eğimi Geleceğin Hekimlerinin Ruh Sağlığı Sorunu Olan Bireylere Yönelik Tutumlarını Etkilemekte midir? Turk Psikiyatri Dergisi. 2010;21:114-25.

9. Bobo WV, Nevin R, Greene E, et al. The effect of psychiatric third-year rotation setting on academic performance, student attitudes, and specialty choice. Academic Psychiatry, 2009;33(2):105-111. https://doi.org/10.1176/appi.ap.33.2.105

10. Ucok A. Other people stigmatize... but, what about us? Attitudes of mental health professionals towards patients with schizophrenia. Archives of neuropsychiatry. 2007;44:108-16. 
11. Nielsen AC. Medical students' attitudes about psychiatry: Implications for psychiatric recruitment. Archives of General Psychiatry. 1981;38(10):1144-54. https://doi.org/10.1001/archpsyc.1981.01780350078009

12. Balon R, Franchini GR, Freeman PS, et al. Medical students' attitudes and views of psychiatry. Academic Psychiatry. 1999;23(1):30-36. https://doi.org/10.1007/BF03340033

13. Altınbaş K, Gülkösüz S, Atbaşoğlu C. Akademik Psikiyatri. 14.Bahar Sempozyumu Bildiri Kitapçığı, 2010.

14. Kobau R, Dilorio C, Chapman D, et al. Attitudes about mental illness and its treatment: validation of a generic scale for public health surveillance of mental illness associated stigma. Community Mental Health Journal. 2010;46(2):164-176. https://doi.org/10.1007/s10597009-9191-x

15. Angermeyer MC, Matschinger H, Schomerus G. Attitudes towards psychiatric treatment and people with mental illness: changes over twodecades. The British Journal of Psychiatry. 2013;203(2):146-51. https://doi.org/10.1192/bjp.bp.112.122978

16. De Toledo Piza Peluso É, Blay SL. Public beliefs about the treatment of schizophrenia and depression in Brazil. International Journal of Social Psychiatry. 2009;55(1):16-27. https://doi.org/10.1177/0020764008092351

17. Lauber C, Nordt C, Falcato L, et al. Lay recommendations on how to treat mental disorders. Social psychiatry and psychiatric epidemiology. 2001;36(11):553-6. https://doi.org/10.1007/s001270170006

18. Angermeyer MC, Matschinger H. Public attitude towards psychiatric treatment. Acta Psychiatrica Scandinavica. 1996;94(5):326-36. https://doi.org/10.1111/j.1600-0447.1996.tb09868.x

19. Wood JH, Chambers M, White SJ. Nurses' knowledge of and attitude to electroconvulsive therapy. The journal of ECT. 2007;23(4):251-254. https://doi.org/10.1097/yct.0b013e31813e0692

20. Calvert SH, Sharpe M, Power M, et al. Does undergraduate education have an effect on Edinburgh medical students' attitudes to psychiatry and psychiatric patients? The Journal of nervous and mental disease. 1999;187(12):757-61. https://doi.org/10.1097/00005053-199912000$\underline{00010}$

21. Sartorius N, Gaebel W, Cleveland HR, et al. Psikiyatri ve psikiyatristlerin damgalanma ile nasıl mücadele edileceği üzerine WPA Kilavuzu. Word Psikiyatri. 2010;9(3):131-45.

22. Williams A, Cheyne A, MacDonald S. The public's knowledge of psychiatrists: questionnaire survey. The Psychiatrist. 2001;25(11):429-32. https://doi.org/10.1192/pb.25.11.429

23. Angermeyer MC, Holzinger A, Matschinger H. Mental health literacy and attitude towards people with mental illness: a trend analysis based on population surveys in the eastern part of Germany. European Psychiatry. 2009;24(4):225-32. https://doi.org/10.1016/j.eurpsy.2008.06.010

24. Thornicroft G, Rose D, Mehta N. Discrimination against people with mental illness: what can psychiatrists do? Advances in psychiatric treatment. 2010;16(1):53-9. https://doi.org/10.1192/apt.bp.107.004481

25. Guttmann F, Rosca-Rebaudengo, P, Davis H. Changes in attitudes of medical students towards psychiatry: an evaluation of a clerkship in psychiatry. The Israel journal of psychiatry and related sciences. 1996;33(3):158-66.

26. Lambert TW, Turner G, Fazel S, et al. Reasons why some UK medical graduates who initially choose psychiatry do not pursue it as a longterm career. Psychological medicine. 2006;36(5):679-84. https://doi.org/10.1017/S0033291705007038

27. Maidment R, Livingston G, Katona M, et al. Carry on shrinking: career intentions and attitudes to psychiatry of prospective medical students. The Psychiatrist. 2003;27(1):30-32. https://doi.org/10.1192/pb.27.1.30

28. Emül M, Dalkıran M, Uzunoğlu S, et al. Tıpta uzmanlık sınavına hazırlanan öğrencilerin psikiyatri asistanlığı hakkındaki tutumları. Düşünen Adam Psikiyatri ve Nörolojik Bilimler Dergisi. 2010;23(4):223-9. https://doi.org/10.5350/DAJPN2010230401

29. Balon, R. Does a clerkship in psychiatry affect medical students' attitudes toward psychiatry? Academi Psychiatry. 2008;32(2):73-75. https://doi.org/10.1176/appi.ap.32.2.73

30. Reddy JP, Tan SMK, Azmi MT, et al. The effect of a clinical posting in psychiatry on the attitudes of medical students towards psychiatry and mental illness in a Malaysian medical school. Annals-Academy of Medicine Singapore. 2005;34(8):505-10.

31. Fischel T, Manna H, Krivoy A, et al. Does a clerkship in psychiatry contribute to changing medical students' attitudes towards psychiatry? Academic Psychiatry. 2008;32(2):147-150. https://doi.org/10.1176/appi.ap.32.2.147

32. Maidment R, Livingston G, Katona C, et al. Change in attitudes to psychiatry and intention to pursue psychiatry as a career in newly qualified doctors: a follow-up of two cohorts of medical students. Medical teacher. 2004;26(6):565-69. https://doi.org/10.1080/01421590410001711562

33. Abramowitz MZ, Bentov-Gofrit D. The attitudes of Israeli medical students toward residency in psychiatry. Academic Psychiatry. 2005;29(1):92-5. https://doi.org/10.1176/appi.ap.29.1.92

34. Malhi GS, Parker GB, Parker K, et al. Attitudes toward psychiatry among students entering medical school. Acta Psychiatrica Scandinavica. 2003;107(6):424-9. https://doi.org/10.1034/j.1600-0447.2003.00050.x 